\title{
Bolívar y la Iglesia en el Perú: la cuestión del Patronato
}

Bolivar and the Church in Peru: the issue of the «Patronato real»

Elizabeth HERNÁNDEZ GARCÍA

Universidad de Piura, Perú

elizabeth-hernandez@udep.pe

\begin{abstract}
When independence was proclaimed in the various cities of the Viceroyalty of Peru (1820-1821), this sparked problems in the Church, the most important being the forced or voluntary exile of bishops, canons and many parish priests. San Martín (18211822) and Bolivar (1823-1826) both took upon themselves the prerogatives of the «Patronato real». But it was under Bolívar that the church in Peru lost more authority: his period saw the most radical exercise of this patronage. This article studies some of the measures that Bolivar applied to control the clergy in Peru, as well as the consequences of this policy.
\end{abstract}

Keywords: Independence; church; clergy; bishops; state; Peru; Spanish America.
Resumen: Cuando empezó a proclamarse la independencia en las distintas ciudades del Virreinato del Perú (1820-1821), también se iniciaron los problemas en la esfera eclesiástica, siendo el más notorio el exilio de obispos, canónigos y muchos curas párrocos. Tanto San Martín como Bolívar asumieron las prerrogativas del Patronato Regio. Pero fue con Bolívar con quien la Iglesia vio perder autoridad y con quien el Patronato se ejerció con mayor radicalidad. Este artículo estudia algunas medidas que el libertador venezolano aplicó para controlar al clero en el Perú, así como las consecuencias que dicha política generó en este estamento.

Palabras clave: Independencia; iglesia; clero; obispos; Estado; Perú; Hispanoamérica.

\section{INTRODUCCIÓN}

Cuando José de San Martín abandonó el Perú dejando el gobierno en manos del primer Congreso Constituyente, en septiembre de 1822, se inició en la naciente república un período de gran conflicto político. La causa patriota no conseguía consolidarse y transformarse en convicción profunda y triunfo militar; mientras tanto un fortalecido virrey La Serna, desde la sierra central, amenazaba con una contrarrevolución, pasando de la amenaza a la acción pocos meses después.

El provocador ingreso del general realista Canterac a la ciudad de Lima, la huida del poder ejecutivo y legislativo a la fortaleza del Callao (junio 1823), la deposición del presidente José de la Riva-Agüero y el nombramiento de José Bernardo de Tagle en su lugar, entre muchos otros acontecimientos, fueron las circunstancias de gravedad que rodearon el ingreso de Simón Bolívar al Perú. 
El Perú se hallaba profundamente dividido y la elite peruana en general sentía animadversión por el libertador venezolano ${ }^{1}$. De la misma manera que aconteció con San Martín, Bolívar no entró a una Lima triunfante, sino a una Lima asustada, que ansiaba recuperar el orden perdido ${ }^{2}$; una ciudad que siempre buscó la seguridad, la que en ese momento Bolívar representaba, a pesar del recelo que su figura despertaba ${ }^{3}$.

Una vez que la capital -las clases dirigentes- demostró que la lealtad a la patria dependía de cómo se moviesen las aguas, abriendo las puertas a los realistas en febrero de 1824, Simón Bolívar inició con mucha más fuerza y firmeza la ofensiva militar y la organización administrativo-política del Perú camino a la independencia total ${ }^{4}$. En ese camino el clero seguía siendo fundamental. Esa fuerza dictatorial había sido aplicada en el estamento eclesiástico por José de San Martín, pero ahora el patriotismo de todos, y antes que nada de los sacerdotes y religiosos, era cuestión de vital importancia para el Estado. La reeducación política de la población dependía de la influencia ideológica que la Iglesia y sus miembros tuviesen sobre ella. Del mismo modo que el libertador argentino, Bolívar asumió para sí la institución del Patronato Regio; era la única manera de conseguir el control. Paralelamente, la Iglesia en el Perú se encontraba en una situación muy inestable y crítica.

Los obispados y obispos en el Perú que llegaron a la independencia eran los siguientes: Lima (Bartolomé de Las Heras), Trujillo (José Carrión y Marfil),

1 Bolívar había ofrecido antes su colaboración a los dirigentes peruanos, pero su ofrecimiento no solo fue rechazado, sino que la prensa peruana lo vilipendió. «Parece que los miembros del gobierno nos tienen más celos a nosotros que a los españoles», comentó. John LYNCH, Simón Bolívar, Crítica, Barcelona, 2006, p. 246.

2 El recibimiento a Simón Bolívar fue muy grande, pues se tenía esperanza en que él pudiese solucionar el nudo gordiano en que se había convertido la capital. «Las descargas de artillería, el clamoreo de las campanas, las aclamaciones entusiastas lo acompañaron al cruzar las calles hasta llegar a la casa que se le había preparado... Los banquetes y los brindis solemnizaron aún más tan importante acontecimiento, como queriendo borrar las desilusiones y los padecimientos del pasado y las angustias y las incertidumbres del presente». Jorge BASADRE, Historia de la República del Perú, $7^{\mathrm{a}}$ ed., Editorial Universitaria, Lima, 1983, pp. 31-32. La cursiva es nuestra.

$3 \ll$ y aseguran que es muy violento al caminar, y con esta prevención estamos con la barba al hombro...» «A Bolívar lo hacen cerca de Piura, y aquí hay mil opiniones, Dios nos saque con bien de todo». Carta a Tomás Diéguez (Piura, Trujillo, 1830), en LIMA-ARCHIVO GENERAL DE LA NACIÓN (AGN), col. «Tomás Diéguez», caja 9, carp. 29, doc. 24 y 30, ff. 1-1v.

4 El Congreso de la República del Perú, el 10 de febrero de 1824, le concedió el poder político y militar, anunciando esta institución que entraba en receso hasta que Bolívar lo volviese a convocar. De esta manera, se iniciaba la dictadura bolivariana y, como se advierte, se dejaba prácticamente sin atribuciones al presidente de la república, José Bernardo de Tagle. 
Huamanga (Pedro Gutiérrez de Cos), Maynas (José Hipólito Sánchez Rangel), Cuzco (José de Orihuela) y Arequipa (José Sebastián de Goyeneche). Para 1823, año en el que desembarcó Bolívar en el Callao, los tres primeros habían sido enviados al exilio y el obispo de Maynas se había ido voluntariamente en cuanto tuvo noticia de que los patriotas se acercaban a su diócesis, quedando únicamente Orihuela y Goyeneche como cabezas de la Iglesia en el Perú. Con el Patronato Regio vigente era imposible nombrar nuevos obispos sin enemistarse políticamente con la Santa Sede.

El Patronato Regio, por ende, fue un problema de primer orden en las agendas políticas de la época ${ }^{5}$. El que un pueblo se haya quedado sin pastor a causa de los movimientos independentistas hacía peligrar la legitimidad de la independencia, de las autoridades establecidas y del nuevo orden por el que se había apostado, mal que bien. Esta contrariedad se intentó solucionar con el nombramiento de gobernadores eclesiásticos, personas que muchas veces se desempeñaban como deanes y que eran de la confianza de los obispos salientes ${ }^{6}$. El nuevo gobierno sancionaba así una situación que los propios obispos, en algunos casos, habían previsto al depositar expresamente su confianza en estas autoridades antes de partir al exilio.

No hay que olvidar que hasta la capitulación de Ayacucho (9 de diciembre de 1824) el Perú se hallaba dividido en Perú independiente y Perú realista, o también en Perú republicano y Perú monárquico, dado que el virrey José de La Serna aún se encontraba acantonado en la sierra central y sur. De esta manera el problema de la expulsión o salida voluntaria de los obispos también afectaba al bando realista. Por ello, hallándose aún bajo las armas del rey algunas parroquias del Arzobispado de Lima, el virrey La Serna dirigió desde el Cuzco (1822) una carta a las autoridades políticas y eclesiásticas de su jurisdicción, haciéndoles saber que en virtud del Real Patronato, ordenaba que el obispo de Arequipa, José Sebastián

5 Por ejemplo, en México se afirmaba, en un informe leído en el Congreso Constituyente en 1823, que los negocios eclesiásticos estaban paralizados porque no se tenía contacto con Roma. La situación en este estado también era complicada, desolador en palabras de Soberanes, pues, de diez sedes episcopales con que contaba México al momento de la independencia, para 1821 solo cuatro tenían titular, y para 1829 no quedaba un solo obispo. José Luis SOBERANES, La cuestión religiosa en los primeros constituyentes mexicanos, en Josep-Ignasi SARANYANA y Juan Bosco AMORES (eds.), Política y religión en la independencia de la América bispana, Universidad de Navarra-Biblioteca de Autores Cristianos, Madrid, 2011, p. 47.

6 Como era el caso de Tomás López de Ubillús, deán del cabildo catedralicio de Huamanga, que quedó como gobernador eclesiástico de esa diócesis a la salida del Perú del obispo Pedro Gutiérrez de Cos, en diciembre de 1821. La relación entre ambos era muy estrecha, al ser naturales de la ciudad de Piura. 
de Goyeneche, asumiera las funciones y prerrogativas del obispo de Lima, y que el gobernador eclesiástico de Huamanga se haga cargo de la parte del Arzobispado de Lima no sujeta a los patriotas, en tanto se daba cuenta de todo esto al Rey ${ }^{7}$.

El gobierno republicano, por lógicas razones de autoridad, no aprobó esta situación, manteniendo la acefalia de la Iglesia en el Perú. Es evidente que en estas circunstancias el problema eclesiástico se había convertido más en una cuestión de Estado que de fe y de religiosidad, e importaba más quién obtuviese el control que quién garantizase la protección pastoral.

Los acontecimientos políticos fueron condicionando variados problemas eclesiásticos, los que justo calzaban con las principales prerrogativas reales del Patronato, a saber: impedimentos formales para la comunicación directa de los obispos americanos con la Santa Sede; derecho de presentación de clérigos para los beneficios eclesiásticos; intervención en el control económico de la Iglesia (diezmos, obvenciones, montos de los recursos eclesiásticos); y potestad de imponer exacciones económicas a esta a criterio de la autoridad pública ${ }^{8}$. En los álgidos tiempos de la revolución americana, las autoridades políticas tuvieron que adjudicarse esas atribuciones. Por ejemplo, desde 1821 los curatos de las provincias independientes fueron sujeto de exacciones monetarias y de sustracción de alhajas para la causa de la guerra. Son incontables los reclamos de los párrocos acerca de la imposición monetaria que tenían que cubrir, montos que se habían fijado sin considerar la situación real de la provincia en cuestión?.

En abril de 1821, por ejemplo, el gobierno republicano exigió grandes contribuciones en calidad de empréstito a los curas párrocos de Piura, norte del Perú. Las cantidades en general eran exorbitantes, pero sobre todo para el cura de Ayabaca, quien tendría que prestar 4.000 pesos; los de Frías, Huancabamba, Cumbicus, Sechura, Colán y Piura, 1.000 pesos. En total, se esperaba recaudar 14.600 pesos, a lo que se agregarían los fondos de fábrica, la plata de la caja de censos, el

7 Rubén Vargas Ugarte, Historia de la Iglesia en el Perú, t. V, Imprenta de Aldecoa, Burgos, 1962, pp. 71-72.

8 Ernesto Rojas IngUNZA, El báculo y la espada. El obispo Goyeneche y la Iglesia ante la «Iniciación de la República», Perú 1825-1841, Instituto Riva-Agüero, Fundación M.J. Bustamante De la Fuente, Lima, 2006, p. 74.

9 En el caso de las exacciones monetarias, aquí se cuestionaron por el mero tema económico, no por la posibilidad incidir en penas canónicas, como sí pasó en Chile. José Ignacio Cienfuegos zanjó el asunto argumentando que, en el nuevo gobierno, todas las clases sociales gozan de beneficios civiles, muy especialmente el clero. Actuaban, entonces, como verdaderos hijos de la Iglesia, cuyo espíritu caritativo la impulsaba a subvenir las necesidades de sus paisanos y del país. Lucrecia ENRÍQUEZ, El clero y la independencia de Chile, en Josep-Ignasi SARANYANA y Juan Bosco AMORES (eds.) Política y religión..., op. cit., pp. 206-207. 
ramo de bulas y el de cuartas, es decir, prácticamente todos los ingresos efectivos y potenciales de las parroquias ${ }^{10}$. Sin embargo, dichos cupos no se cobraron en su totalidad, pues los curas concedieron mucho menos de lo adjudicado ${ }^{11}$. Esta política se mantuvo todos estos años. Cuando el Cuzco juró la independencia luego del triunfo en Ayacucho, los patriotas exigieron al clero la colaboración de 8.000 pesos; más adelante se pidieron 4.000 más para preparar el ingreso de Bolívar, y así luego 4.000 más por otras razones ${ }^{12}$.

Las erogaciones monetarias no solo buscaron agenciar de recursos al tesoro fiscal. Con la finalidad de demostrar poder frente al recio obispo Goyeneche, Simón Bolívar exigió de esta familia arequipeña mucho dinero, teniendo los Goyeneche que depositar en menos de 15 días la cantidad de 25.000 pesos $^{13}$. Aunque es verdad que se recurrió siempre a las familias pudientes para agenciar de recursos al erario, era mucho dinero para la época, habida cuenta de que en otros espacios, como mencionábamos, a todo el clero de una ciudad se le exigió abonar 8.000 pesos para la guerra. Y aún más.

En su intento por conseguir la última victoria contra España, Simón Bolívar recurrió a las iglesias dependientes del obispado de Trujillo. Así, reservando tan sólo las alhajas más precisas, en septiembre de 1823 ordenó que se despojasen los templos del oro y plata que les enriquecían. La requisa se hizo sistemáticamente y, en principio, por vía de préstamo, tomándose nota del número de marcos de plata y onzas de oro que se sustrajeron, suscribiendo el acta los párrocos o rectores de Iglesia y los comisionados nombrados por el gobierno. Poco tiempo después, el 9 de abril de 1824 se hizo un nuevo secuestro por orden de Bolívar. Aún de la parroquia más pobre se extrajeron marcos de plata. Las iglesias fueron obligadas a conceder una considerable fortuna para auxiliar al ejército patriota ${ }^{14}$.

La independencia, de una o de otra manera, tocó a todos los sectores y estratos de la sociedad. Era lógico que afectara más a aquellos que ostentaban mayores caudales monetarios o bienes muebles e inmuebles. La guerra significó expolio y pérdidas materiales cuantiosas entre muchas familias, emporios mercantiles,

$10 \ll$ Empréstito forzoso para las necesidades del Estado designado a los venerables curas del partido de Piura» (Piura, 1821), en ARChIVO REgIONAL DE PIURA (ARP), Serie: Gobierno Político Militar, leg. 12, exp. 219 , f. 9.

11 Elizabeth HeRnández García, La elite piurana y la independencia del Perú. La lucha por la continuidad en la naciente república (1750-1824), Instituto Riva-Agüero, Pontificia Universidad Católica del Perú, Universidad de Piura, Lima, 2008, p. 339.

12 Rubén Vargas UgarTe, Historia de la Iglesia..., op. cit., p. 75.

13 Ernesto ROJAS INGUNZA, El báculo y la espada..., op. cit., p. 74.

14 Rubén Vargas UgarTe, Historia de la Iglesia..., op. cit., t. v, pp. 82-84. 
grandes y medianos comerciantes, nobles, militares y burócratas. Y también significó la pérdida de poder económico de la institución eclesiástica. Cuando la guerra terminó, la Iglesia se hallaba empobrecida. No hay cálculos exactos de estas pérdidas, pero en general se advierte que muchas de sus propiedades -conventos, hospitales, colegios, haciendas inclusive- dejaron de funcionar durante un tiempo o definitivamente; otras, sin más, se perdieron por las expropiaciones y la dinámica misma de la guerra ${ }^{15}$.

La guerra por la independencia generaba más gastos cada día y año que se dilataba. Si bien es cierto, las «contribuciones» monetarias no gustan mucho por muy adicto que uno sea a una idea política. En este caso, a esta contrariedad se suma una mayor: la injerencia del estado en el estamento eclesiástico, en determinaciones que correspondía dilucidar a otras autoridades. Este tema es muy importante, en tanto que la mentalidad de la época implicaba una relación secular, y por tanto considerada legítima, entre la Iglesia y las instancias políticas virreinales; esa vinculación no se cuestionaba, formaba parte de la tradición. En cambio, lo que el nuevo gobierno hacía era claramente un atentado al orden y a la autoridad eclesiástica. Este orden se siguió resquebrajando y con asuntos de mayor gravedad que la simple exigencia de monetario.

\section{SIMÓN BOLÍVAR Y LAS REFORMAS ECLESIÁSTICAS}

Fue con la dictadura de Bolívar ${ }^{16}$ cuando la Iglesia se sintió más presionada y violentada en el manejo tradicional de su propia corporación. El clero, se sabía muy bien, era fundamental como ejemplo en el cual la población fijaba su atención y a quien podían seguir, a quien de hecho siguieron en multitud de ocasiones ${ }^{17}$.

15 Luis GÓmez ACUÑA, Iglesia y Emancipación en el Perú: Claves interpretativas (1808-1825), en Fernando ARMAS Asín (comp.), La construcción de la Iglesia en los Andes (siglos XVI-XX), Pontificia Universidad Católica del Perú, Lima, 1999, p. 381.

16 Frente a la situación caótica en la que se encontraba el Perú y, en concreto la ciudad de Lima cuando las tropas patriotas se amotinaron en el Real Felipe, fue que el Congreso de la República le concedió el poder dictatorial, el 5 de febrero de 1824.

17 Por ejemplo, la feligresía paiteña no estuvo de acuerdo con la supresión del convento de mercedarios de aquel puerto, se pusieron del lado de los religiosos originando una situación complicada para el Poder Ejecutivo. Elizabeth HERNÁNDEZ GARCÍA, Hacia el control del clero piurano: la reforma de regulares de 1826 en el norte del Perú, en Francisco CERVANTES, Lucrecia ENRÍQueZ y Rodolfo AGUIRRE (eds.), Tradición y Reforma en la Iglesia hispanoamericana 1750-1840, México, 2012, pp. 83-112. 
La consumación de la independencia no era sinónimo de tranquilidad sino de incertidumbre. Estaba claro que ahora las decisiones políticas que tuvieran que ver con la Iglesia dependerían de la simpatía y de las necesidades del gobierno, de la afinidad o de la animadversión que se generara en el ánimo del Poder Ejecutivo. De nada serviría oponerse. La monarquía dejó de ser una opción; la república era una realidad.

Las diócesis que se encontraban aún en poder realista hasta fines de 1824, tuvieron que jurar la independencia por la patria ante el triunfo definitivo de Bolívar. Es este el primer cambio radical en la mentalidad de las autoridades eclesiásticas del centro y sur andino. No había alternativa si lo que se quería era estar del lado del hombre fuerte, considerando que ya el virrey La Serna se había despedido del Perú, vencido, y que el fuerte del Real Felipe del Callao se hallaba sitiado por los patriotas ${ }^{18}$. De esta manera, en Arequipa se interesaron mucho por asegurar la adhesión política del clero, condicionando la pronta juramentación de sus miembros.

En las provincias que se habían mantenido realistas hasta la batalla de Ayacucho, el gobierno intervino estableciendo una Junta de Calificación para analizar la trayectoria política de los sacerdotes ${ }^{19}$, a semejanza de la Junta que en su momento inauguró el Protectorado de San Martín (1821-1822) y por la que se examinó a curas de distintas partes del Perú independiente. Era el proceso que faltaba a las provincias recién patriotas, las cuales buscaron también «limpiar»su anterior imagen. Paralelamente a la Junta, varias reformas más se fueron dando.

El 15 de noviembre de 1825 se decretó la intervención de la autoridad civil nada menos que en la recaudación de los derechos parroquiales de los indígenas, en el supuesto de la arbitrariedad de los párrocos en su cobranza. De manera que la secuencia sería: el indígena pagaría, el párroco le extendería una papeleta registrando el pago, esa papeleta sería examinada por la autoridad civil, y esta la devolvería al indígena con sus objeciones o con su visto bueno ${ }^{20}$. Una intromisión en toda regla del Estado bolivariano en las parroquias de indios. Si bien podríamos decir que esta medida velaba por los intereses de los naturales, era también la afirmación de la política sobre el clero.

18 El realista José Ramón Rodil entregó el Real Felipe en enero de 1826, luego de poco más de un año de una resistencia absurda y frenética, en la que, se calcula, murieron entre 3.000 y 6.000 personas por inanición y enfermedades infecto-contagiosas.

19 Ernesto Rojas IngUnZa, El báculo y la espada..., op. cit., p. 74.

20 Pedro Grases (ed.), Gaceta del Gobierno del Gobierno del Perú. Período de gobierno de Simón Bolívar, t. III (1825-1826), Fundación Eugenio Mendoza, Caracas, pp. 173-174. 
Bolívar dispuso en temas de demarcaciones territoriales de las diócesis: incorporó a la sede del Cuzco las provincias de Chucuito y de Huancané que pertenecían antes al obispado de La Paz ${ }^{21}$. Según Vargas Ugarte, era esta una medida tomada como consecuencia de la división del Alto y Bajo Perú por la creación de la República de Bolivia ${ }^{22}$. La distribución limítrofe de las diócesis y las obligaciones pastorales de tal o cual ministro del altar con cada una de ellas no correspondía al jefe de gobierno republicano. Además, esta nueva organización, aunque se tratase únicamente de dos provincias, condicionaba elementos no menos importantes: un nuevo mapa de la diócesis, nuevas fronteras territoriales y mentales, nuevos conflictos en el día a día en paralelo a la asimilación de estos cambios. Fue un maltrato más el que sintieron en su dignidad los obispados a los que solo les correspondía obedecer.

De otro lado, por orden de Bolívar también se redujeron en un tercio los derechos parroquiales, adoptándose un nuevo arancel. A esto reaccionó Orihuela, obispo del Cuzco, quien propuso se sustituyese esta contribución por una tasa que habían de pagar los feligreses en proporción al haber que gozaban. Obviamente, no se tomó en cuenta esta sugerencia. Se trataba de una clarísima intromisión, por lo que el gobierno siguió siendo mal visto, sobre todo porque, en el fondo, se podía intuir que no necesariamente se buscaba el bien de las diócesis sino el manejo del clero. Y en este intento se continuó actuando.

En julio de 1825 se acometió otra reforma, pues se suprimieron en el coro del Cuzco dos dignidades, la de Maestrescuela y la de Chantre y además una canonjía de merced, a fin de que las rentas de estos prebendados se distribuyesen entre los demás por la disminución de sus remuneraciones. Esta última justificación nos hace leer entre líneas que hubo muchas voces que se elevaron por la poca regularidad en los sueldos de los miembros del cabildo catedralicio. La falta de pagos era el día a día desde 1820, como nos lo comenta el presbítero Francisco de Carrión e Iglesia, prebendado de la catedral de Lima, quien mencionaba en su testamento «... el beneficio que me hubiera prestado la prebenda que sirvo para el mejor descanso, lo ha impedido las circunstancias del día, y hallarse generalmente suspenso el pago a todos los beneficiados $»^{23}$. Aunque la intención no fuese más que la inmediatez en la solución de problemas, los conflictos entre la autoridad política y el clero, y entre los propios canónigos, condicionó muchas decepciones y desencuentros.

21 Pedro Grases (ed.), Gaceta del Gobierno..., op. cit., t. III, p. 113.

22 Rubén Vargas Ugarte, Historia de la Iglesia..., op. cit., t. V, p. 73.

23 «Testamento de Francisco Félix de Carrión e Iglesia» (Lima, 1823), en AGN. Serie: Notarial. Notario: Julián de Cubillas. Prot. 203, f. 2. 
Ante todas estas acciones, el obispo del Cuzco decidió hacerse a un lado. Le manifestó al Libertador que estaba decidido a entregar el gobierno de la diócesis. Hizo lo más acorde a su criterio proponiendo como deán y gobernador del obispado a Patricio Menéndez y a Matías Alday. Pero Bolívar no aceptó a ninguno de estos dos y dio el cargo a Pedro Antonio Torres ${ }^{24}$. José Calixto de Orihuela se dirigió a Lima y se retiró a la casa de ejercicios espirituales de Nuestra Señora de la Consolación, casa que él había fundado. Falleció allí en 1841.

El obispo del Cuzco, aunque no se fuese del Perú, renunció a sus facultades como cabeza de uno de los obispados más importantes, uno de los que había resistido más tiempo de la mano del virrey La Serna. Podemos deducir que la presión a que estuvo sometido Orihuela fue considerable: se trataba de abandonar una forma de pensar y de hacer en la que se había formado toda su vida. De otro lado, todo lo acontecido él lo consideraba vejaciones a su investidura. De hecho, ni siquiera ante su renuncia Bolívar dio su brazo a torcer, nombrando a otro en lugar de los nombres recomendados por el obispo. La renuncia de Orihuela evidencia, además, el choque de mentalidades entre uno y otro sistema, una y otra época si se quiere, pues aun habiendo firmado una pastoral y formalmente estar de acuerdo con la independencia, fue incapaz de continuar en ese régimen.

Pero no solo se trató de eliminar prebendas para poder pagar los sueldos. Como una manera de reconocer la contribución que la ciudad de Trujillo, en el norte del Perú, había dado a la causa de la libertad ${ }^{25}$, Bolívar erigió la canonjía supresa de la Inquisición, restableciéndola en la dignidad de Maestrescuela de esa Iglesia; además, convirtió en medias raciones las dos capellanías de coro que se denominaban reales.

Así el Senado de la Catedral de Trujillo queda condecorado de un modo que hará conocer a la diócesis que S.E. el Libertador sabe remunerar... los servicios y virtudes de los pueblos que con firmeza y dignidad han sabido sostener su Independencia.... ${ }^{26}$.

Bolívar actuaba con la liberalidad que le daba el poder dictatorial. Bajo ningún punto de vista tenía atribuciones para variar la conformación del cabildo eclesiástico. Sin embargo, con el argumento de la fidelidad de Trujillo, dio paso

24 Rubén VArgas UGarTe, Historia de la Iglesia..., op. cit., t. V, pp. 75-76.

25 Cuando la ciudad de Lima fue tomada nuevamente por los realistas en febrero de 1824, y los altos mandos civiles y militares ahí situados se pasaron a las filas del virrey, Simón Bolívar hizo del norte su centro de operaciones. Trujillo cambió de nombre, pasó a llamarse «Ciudad Bolívar».

26 AGN, Sección: Real Justicia, leg. 149, exp. 13, año 1827, f. 1. 
a estas medidas. No hay respuesta de parte del alto clero trujillano a esta comunicación, por el momento ${ }^{27}$.

Volviendo al espacio del Bajo Perú, Simón Bolívar había nombrado como obispo del Cuzco a quien consideró mejor opción que los nombres propuestos por Orihuela. Y es que aquí se manifestó otro gran problema: la fragilidad del régimen. No olvidemos que la consumación de la independencia peruana no fue una celebración nacional; Bolívar lo sabía: luchó contra España y también contra una parte significativa del Perú ${ }^{28}$. Por esta razón tenía que combinar en la elección de candidatos dos factores imprescindibles: identificación con la «patria»e idoneidad, en ese orden y en todos los niveles. Alto y bajo clero fueron puestos en tela de juicio y, paralelamente, fueron reestructurados.

\section{LOS MINISTROS DE LA IGLESIA Y LA FIDELIDAD A LA NUEVA PATRIA}

En enero de 1827, quedando vacante el arcedianato de Trujillo ${ }^{29}$, se determinó que se proveyera en el trujillano Tomás Diéguez Florencia. Este nombramiento por parte del Estado es significativo desde toda perspectiva. Hasta ese momento, Diéguez se hallaba al margen de la elite eclesiástica; era únicamente cura párroco de Catacaos - distrito de Piura-, esto es, formaba parte del bajo clero. Ya el año 1825 el gobierno de Bolívar le había adjudicado una «canonjía de gracia» en el cabildo eclesiástico de Trujillo, pero renunció a ella por motivos de salud, habiendo dejado pasar bastante tiempo e impidiendo que otro pudiese obtener esta merced.

Nos centramos brevemente en este caso porque Tomás Diéguez tuvo una gran importancia en el norte del Perú. El tiempo que ejerció de vicario eclesiástico en Piura (1808-1825), estuvo presente en distintos acontecimientos, desde

27 Elizabeth HERnÁNDEZ GARCÍA, Nuevo régimen, «seculares» problemas: el clero en Trujillo independiente, una aproximación (1821-1830), en Revista Peruana de Historia Eclesiástica, 13 (2011), pp. 107-108.

28 Timothy ANNA, La caída del gobierno español en el Perú. El dilema de la independencia, Instituto de Estudios Peruanos, Lima, 2003. John LYNCH, Simón Bolívar, Crítica, Barcelona, 2006. Scarlett O'Phelan Godoy, Sucre y Bolivar: entre Riva-Agüero y Torre Tagle, en Scarlett O'PHELAN GODOY (comp.), La independencia del Perú. De los Borbones a Bolívar, Pontificia Universidad Católica del Perú, Instituto Riva-Agüero, Lima, 2001, pp. 379-406. Gustavo MoNTOYA, La independencia del Perú y el fantasma de la revolución, Instituto Francés de Estudios Andinos, Instituto de Estudios Peruanos, Lima, 2002.

29 Quedó vacante porque quien lo ocupaba, Carlos Pedemonte, fue promocionado como Arzobispo de Lima, otro nombramiento de Simón Bolívar. 
la jura a Fernando VII y a la Constitución de 1812, hasta las reuniones previas a la declaración de la independencia en Piura, en enero de $1821^{30}$. Pero se hallaba fuera de las cerradas paredes del cabildo catedralicio cuando el gobierno lo elevó al arcedianato de Trujillo. ¿Por qué razón, entonces, se le llevó a ese sitial? El puesto debía tenerlo un «... eclesiástico de mérito y patriotismo...», cosas que concurrían en Diéguez según el informe oficial, además de tener «... las mejores cualidades para servirla [la dignidad], y la circunstancia de haber desempeñado cumplidamente la Diputación en el Congreso Constituyente» ${ }^{31}$. En el mismo decreto, el gobierno nombraba como Maestrescuela, dignidad recién restaurada, al piurano Pedro José del Castillo, canónigo doctoral de la catedral trujillana. Se decretaba, finalmente, abrir oposición para la canonjía doctoral que quedaba vacante.

En el caso de Tomás Diéguez, su idoneidad para el cargo difícilmente se podía comprobar, pues fue una concesión la que le hizo el gobierno; no hubo concurso en el que pudiera demostrar sus conocimientos frente a otros candida$\operatorname{tos}^{32}$. ¿Qué atributos se vieron en él, entonces? Al parecer, Diéguez estuvo muy cerca del nuevo sistema desde el momento de la independencia del norte, razón que condicionó sus buenas relaciones en la ciudad de Lima; ello luego le permitió este ascenso tan considerable en su carrera.

A diferencia de Tomás Diéguez, Pedro José del Castillo ya formaba parte del alto clero cuando Bolívar lo nombró Maestrescuela. Desde sus primeros años de formación en el Seminario de San Carlos y San Marcelo en Trujillo, tuvo oportunidad de mostrar sus condiciones para el debate y la disquisición teológica; pero los contactos más firmes los consiguió en Lima, al estudiar en los centros de enseñanza más importantes: el Convictorio de San Carlos y la Universidad de San Marcos. Y es que todas las familias de privilegio habían advertido la necesidad de

30 No estuvo presente en el cabildo abierto que decidió proclamar la independencia de la provincia, el 4 de enero de 1821. Respecto a la vida de este eclesiástico, ver: Elizabeth HERNÁNDEZ GARcía, De vicario eclesiástico a obispo de Trujillo: Tomás Diéguez Florencia y su adecuación al orden republicano en el Perú (1776-1845), en Rodolfo AgUIRRE y Lucrecia ENRÍQUEZ (eds.), La Iglesia bispanoamericana, de la colonia a la república, Universidad Nacional Autónoma de México, Pontificia Universidad Católica de Chile, Plaza y Valdés Editores, México, 2009, pp. 279-303.

31 AGN, Real fusticia, leg. 149, exp. 13, año 1827, f. 1.

32 En teoría, pues esta condición no era necesariamente la que primaba en ceremonias de este tipo. Elizabeth HeRNÁNDEZ GARCÍA, Clérigos de provincia en busca de una prebenda: la lucha de los vecinos piuranos por una canonjía en el Perú tardocolonial (1780-1821), en Valentina AYROLO (ed.), Estudios sobre clero iberoamericano, entre la independencia y el Estado-Nación, Centro Promocional de las Investigaciones en Historia y Antropología (CEPIHA), Universidad de Salta, Salta, 2006, pp. $15-45$. 
las relaciones sociales en las ciudades que tenían cabildos eclesiásticos y que eran importantes centros de poder político y económico. ${ }^{33}$ Sin embargo, y no obstante esta trayectoria, el nuevo cargo dado por el Poder Ejecutivo se saltaba también el normal desenvolvimiento de la carrera eclesiástica, convirtiendo a José del Castillo en «usurpador» del puesto que, en opinión del cabildo, le correspondía a otro canónigo.

Podemos intuir la sorpresa e incomodidad que ambos nombramientos despertaron entre los eclesiásticos. El sistema del escalafón se había suspendido en beneficio de personas que no estaban tan cerca de alcanzar dichos lugares. Los clérigos disputaban en hacer méritos por posesionarse de las canonjías, de por sí escasas, y se hallaban a la espera de la vacancia de alguna para presentarse a concurso. El gobierno, Diéguez y del Castillo traían abajo esas ilusiones ${ }^{34}$.

Los miembros del alto clero llegaron a sentirse despojados de su autonomía y de sus tradicionales manejos. Es verdad que para nadie era sorpresa que los concursos públicos no estaban exentos de privilegios, estrategias y profundas rivalidades. Así era desde siempre; era inconcebible que las cosas cambiaran en esta línea. Pero lo que ahora se veía era un gran desorden de privilegios en los que se confundía el patriotismo con el escalafón. Los eclesiásticos elevaron su voz de protesta de manera bastante temeraria considerando la política persecutoria contra los denominados «antipatriotas» y que, ante cualquier circunstancia, el gobierno podía sentirse agraviado.

Dijeron los clérigos: «La escala se observaba tan rigurosamente en el gobierno español, que en Lima vimos a un Baquíjano empezando por Alcalde de Corte, después de haber renunciado varias togas que le dieron en las Chancillerías de España... $\gg^{35}$. Llevaban razón en tanto que, normalmente y exceptuando el período de la venta de nombramientos para puestos públicos, el sistema de ascensos siempre se tuvo como referencia ineludible de méritos. Pero no era este desequilibrio el único motivo de descontento.

La Constitución de 1823 establecía que ningún diputado durante su comisión como tal podría obtener para sí empleo, pensión o condecoración alguna

33 Las relaciones sociales también venían de parte de su hermano, José Miguel del Castillo, que estudió en los mismos centros de enseñanza de Trujillo y Lima; fue Oficial de la Secretaría de Cámara del virreinato peruano (1805), y fue diputado a Cortes Ordinarias por la provincia de Trujillo (1813). Elizabeth HERNÁNDEZ GARCÍA, La elite piurana..., op. cit., p. 409.

34 Elizabeth HERNÁNDEZ GARCÍA, Nuevo régimen, «seculares» problemas: el clero en Trujillo independiente, una aproximación (1821-1830), en Revista Peruana de Historia Eclesiástica, 13 (2011), p. 109.

35 AGN, Real fusticia, leg. 149, exp. 13, año 1827, f. 11. La cursiva es nuestra. 
si no era ascenso de escala en su carrera. Sin embargo, tanto con los clérigos mencionados como con Carlos Pedemonte -a quien luego el gobierno nombró obispo de Lima- se había infringido la ley. Afirmaba el cabildo de Trujillo:

Este artículo [de la Carta Magna]... fue quebrantado a la sombra de la dictadura en 2 de abril de 1824, y el agraciado doctor Pedemonte, durante su primera diputación, obtuvo para sí la dignidad de Arcediano de esta Iglesia, con perjuicio irreparable del Chantre, a quien le correspondía como inmediato ascenso de escala en su carrera ${ }^{36}$.

Aunque a Simón Bolívar se le dieron poderes dictatoriales, la expresión «a la sombra de la dictadura» con que el cabildo hacía su reclamo era claramente desafiante. Para haber llegado a este nivel, el sentimiento de impotencia fue enorme. El tema de los nombramientos que se hicieron como retribución por la cercanía al nuevo sistema, entonces, tiene este otro ángulo de desencanto que es necesario considerar, pues se trataba de clérigos que, no solo se sintieron atacados en su investidura, sino que vieron truncadas sus aspiraciones de toda la vida.

No hay que descuidar un punto más. Gaspar Nieto Polo, chantre, era uno de los presbíteros que más tiempo llevaba en el cabildo de Trujillo, razón por la cual, además, el deán y los canónigos cerraron filas en torno a él, teniéndolo como estandarte de sus reclamaciones. Por la misma razón, si bien buscaban que el gobierno se retracte en la adjudicación de los dos nombramientos eclesiásticos, queda claro que contra quien dirigieron sus ataques fue contra Tomás Diéguez. En particular, el último beneficio de Arcediano que desde Lima se le otorgó había dejado relegado por segunda vez a Gaspar Nieto, también diputado por Trujillo al Congreso de la República. «¿Cuál habrá sido, pues, el pesar y dolor de este mismo Cabildo, al ver por segunda vez, y contra todo lo dicho hasta aquí, postergada la escala del expresado Chantre, por haberse conferido el Arcedianato, nuevamente vacante, al cura de Catacaos, D. D. Tomás Diéguez?.... ${ }^{37}$.

La respuesta del gobierno fue negativa para el cabildo trujillano. Se le ordenó llevar a efecto las gracias concedidas en Tomás Diéguez y en Pedro José del Castillo. Lamentablemente para el cabildo de Trujillo, el sistema se había trastocado y ya no había vuelta atrás. Se equivocaron al pensar que el gobierno iba a dar marcha atrás en lo decretado, habida cuenta de que su objetivo estaba muy claro: el premio a la lealtad. Los canónigos se sentían vejados en su autoridad, en

36 AGN, Real fusticia, leg. 149, exp. 13, año 1827, f. 11.

37 AGN, Real fusticia, leg. 149, exp. 13, año 1827, f. 11v. 
la anterior inviolabilidad de su espacio de poder. Se puede afirmar, por ello, que el cambio de régimen fue una gran conmoción.

Intentando comprender a los miembros del alto clero, lo que vemos es una prestancia mancillada por una autoridad extraña. Nada más alejado de su anterior realidad que el gobierno republicano en estos difíciles años de adaptación ${ }^{38}$. De otro lado, el Ejecutivo con su intromisión estaba generando rencillas y disputas mucho más graves, tal vez, que las que se suscitaban en la época virreinal porque los requisitos para hacerse con un nombramiento incluían otros intereses.

¿El gobierno advertía el choque que desataba dentro de la esfera eclesiástica? Tanto el enfrentamiento entre sus miembros como el impacto psicológico del estamento en su conjunto sí que lo advertía. Aunque las medidas eran improvisadas por las circunstancias del día, el proyecto político no. El fiscal afirmaba en su veredicto: $\ll . .$. cuyas faltas [se refiere al cabildo eclesiástico] son tanto más notables, cuanto que siendo los individuos que componen el coro, los primeros ministros de ella, deben mostrarse sumisos a las leyes y a las autoridades constituidas de la República $>^{39}$. El gobierno, o se extraña de la desobediencia e indocilidad de los miembros del clero, o era una manera de recordarles quién estaba sobre ellos a partir de ahora.

Lo cierto es que, para el gobierno de Simón Bolívar estas injerencias no eran un abuso sino el ejercicio de un derecho. Las acciones y expresiones de los representantes del libertador venezolano daban a entender con claridad que se habían asumido las prerrogativas del Patronato Regio. Así se explica que, escribiendo Faustino Sánchez Carrión, secretario de Bolívar, a Carlos Pedemonte, el 9 de julio de 1824, le diga:

V.S. debe estar altamente penetrado del celo que anima a S.E. el Libertador por los derechos y dignidad de la Iglesia... esté entendido que jamás disimulará nada de lo que pueda desviar al pueblo de la moral evangélica, relajar la disciplina eclesiástica o deslustrar la majestad del Santuario en sí o en sus ministros y que antes bien recibirán de su autoridad estos sagrados objetos toda la protección que debe conforme a la ley fundamental del Estado... ${ }^{40}$.

Moral evangélica y disciplina eclesiástica eran preocupaciones que venían del siglo anterior y de otro régimen, pero que durante y luego de las guerras

38 Elizabeth HERNÁNDEZ GARCÍA, Nuevo régimen, «seculares» problemas: el clero en Trujillo independiente, una aproximación (1821-1830), en Revista Peruana de Historia Eclesiástica, 13 (2011), p. 112.

39 Rubén Vargas UgarTe, Historia de la Iglesia..., op. cit., t. V, p. 76.

40 Citado en ibid., p. 71. 
de independencia cobraron otro cariz. La protección a la que aludía Sánchez Carrión implicaba que la política estaría muy pendiente del pilar que era el estamento eclesiástico en el Perú, mucho más en las provincias del bajo y sur andino por ser las últimas en proclamar la libertad.

Habiendo renunciado Orihuela, con Bolívar solo quedaba el obispo de Arequipa, José Sebastián de Goyeneche, por lo que, según aquel, había que proveerse las sedes vacantes. Así lo hizo. El Libertador nombró como obispos a Pedemonte (Lima), a Echagüe (Trujillo), a Parral (Maynas) y a Fernández de Córdoba (Huamanga). El nombramiento del obispo de Maynas evidencia con claridad que para el gobierno de Bolívar estas determinaciones eran ejercicio de un derecho:

Por cuanto el derecho de Patronato Eclesiástico reside en la Nación y su ejercicio por delegación solemne de sus representantes juntos en Congreso Constituyente en la persona del Libertador Simón Bolívar o en las que este sustituyese... en cuya virtud le incumbe elegir y presentar a los ciudadanos que deben ocupar las prebendas, canonjías, dignidades eclesiásticas, obispados y arzobispados que vacaren en las catedrales y diócesis de la Nación...

El Consejo de Gobierno afirmaba que ya había solicitado a Roma la aprobación canónica ${ }^{41}$.

Además, luego de mucha insistencia Goyeneche finalmente tuvo que redactar la Pastoral pedida por el Libertador a través de la cual aplaudía la libertad y rompía para siempre con España; por ello era que el obispo había tardado bastante en realizar esta tarea ${ }^{42}$, sobre todo por la manera como Bolívar se lo pidió.

La solicitud a Goyeneche en 1825 clarifica la idea que tenía el Estado sobre el papel del clero: «V.S.I... debe... hacer esfuerzos extraordinarios para contribuir a la estabilidad de los principios fundamentales de nuestra regeneración política» ${ }^{43}$. Esta es la expresión clave: «regeneración política». En términos actuales, se trataba de una «reingeniería política» que tendría que pasar necesariamente por las manos del clero, estamento encargado de la educación en los centros de enseñanza formales, en los espacios públicos y privados, en el púlpito y

41 Carlos Larrabure y CORREA, Monumenta Amazónica. Colección de leyes, decretos, resoluciones y otros documentos oficiales referentes al departamento de Loreto, t. VIII, Centro de Estudios Teológicos de la Amazonía (CETA), Gobierno Regional de Loreto (GOREL), Iquitos, 2008, p. 269.

42 «sta tarda docilidad ante el Libertador desvela el sufrimiento íntimo del obispo... esa pastoral no sólo constituyó el punto de ruptura formal del juramento de fidelidad al rey que había realizado al comienzo de su episcopado, sino que significó también un momento de ruptura consigo mismo, con su pasado» (Ernesto ROJAS INGUNZA, El báculo y la espada..., op. cit., p. 68).

43 Ibid., p. 66. 
en el confesionario. El Estado, por su parte, contribuiría con el nombramiento de eclesiásticos «fieles» a la patria, que sirviesen de abanderados del nuevo régimen. Estos, supuestamente, reemplazarían los puestos vacantes. Pero, y aquí tenemos otro problema, ¿realmente habían vacado los sitios?

En el anterior sistema, la vacancia de los puestos eclesiásticos estaba legislada por el Derecho Canónico. Solo el gobierno español, en virtud del Real Patronato, podía nombrar y remover a los curas de sus beneficios. El Ejecutivo, por tanto, no podía reemplazarlos; cualquier paso dado en falso al respecto ponía una barrera más en esa relación que el Estado peruano buscaba retomar con la Iglesia. Como no podían nombrarse párrocos propietarios, Bernardo de Monteagudo, en 1821, sancionó sean colocados párrocos interinos en lugar de los curas españoles removidos. Eso sí, tenían que ser « «... eclesiásticos de regular conducta y de notorio patriotismo, con el que podrá suplirse alguna falta de luces que se notare acaso en cualquiera de los elegidos» ${ }^{44}$.

A pesar de todo, y en medio de la inestabilidad política, no fue tan sencillo conseguir interinos en todos los curatos, quedando muchas doctrinas sin pastor durante largo tiempo. Para el caso de Trujillo, el 8 de febrero de 1825, Simón Bolívar ordenó se realizase el concurso de curatos y sacristías vacantes en ese obispado. Al deán de Trujillo, Juan Ignacio Machado, le surge la duda de si había que proveer los curatos de San Sebastián en Trujillo, de Pallaques en Cajamarca, y de Paita y Colán en Piura, puesto que los párrocos se habían ido del Perú. La consulta del deán es pertinente, en tanto que estos curatos no podían considerarse «vacantes» desde el punto de vista legal. Según el Derecho Canónico, los beneficios colados no vacan sino por muerte, resignación o remoción del beneficiado con justa y probada causa y con intervención de las autoridades políticas y religiosas -se supone del antiguo sistema-. Pero el abandono voluntario o forzado de estos eclesiásticos no calzaba con ninguna de estas causas. Se inicia, entonces, un debate entre las autoridades sobre estos y otros curatos en la nueva república.

El fiscal en su dictamen deja sentado que estos curatos, efectivamente, no están vacantes; recuerda que hasta ese momento el Estado reconocía, por ejemplo, que estaban ocupadas las sillas del arzobispado de Lima y del obispado de Huamanga, apareciendo como tales en la Guía del año en curso - 1825- y no obstante la salida del Perú de ambos prelados. A semejanza de esta situación, el fiscal estimaba que «... los curatos a que se contrae esta consulta, aunque estén vacantes de hecho, no lo están de derecho...». Está desestimando, por tanto, la posibili-

44 AGN, Real fusticia, leg. 149, exp. 9, año 1825, f. 9. La cursiva es nuestra. 
dad de que se sometan a concurso público. Pero, diez días después (11/07/1825) el gobierno de Lima, teniendo en cuenta el dictamen de la Corte Suprema de Justicia, declara que estas doctrinas sí se hallan vacantes y que, por tanto, deben proveerse en propiedad; «... del mismo modo que las de los americanos emigrados que se hallan entre los enemigos, con la única calidad de que sean atendidos oportunamente en otros beneficios, si en algún tiempo pudieren sincerar su conducta política...» ${ }^{45}$. Se está dejando la puerta abierta al posible retorno de estos curas al sistema patriótico; la necesidad de eclesiásticos para la cura de almas y para el gobierno de los pueblos indígenas era enorme.

Con ocasión de una consulta que se realiza sobre otras doctrinas, cuyos párrocos peninsulares igualmente fueron expulsados y se hallaban en España, el fiscal argumenta que aquellos se hallan imposibilitados de residir en su doctrina, condición que sí está expresada como obligación en el Derecho Canónico; agrega además la idea del peligro que sus personas representan al nuevo sistema político y aun al mismo estado eclesiástico, «... cuya lenidad característica podría resentirse en exponer a los pueblos a inundarse en torrentes de sangre...». Finalmente, el fiscal solicita la opinión del gobernador eclesiástico de Lima, Francisco Javier de Echagüe.

A las razones expresadas por el fiscal, Echagüe añadió un elemento más en el intento de vacar esos beneficios: la falta de cartas de ciudadanía de los párrocos expulsados. Esto significaba que se estaba mirando un tema del Patronato Regio con la normativa de la república, asunto carente de legalidad y de sentido. Por un lado, está claro que el Estado no estaba en la capacidad legal de intervenir en asuntos eclesiásticos. Y por otro lado, ¿cómo podían tener carta de ciudadanía curas españoles que fueron expulsados antes de ser emitida esa norma y antes de promulgarse la Constitución Política del Perú? Muestra de esta búsqueda desesperada de razones que validen la posición del Estado, Echagüe se sirve del decreto del Congreso de la República del 10 de marzo de 1825, que incidía en el tema económico: «Que el eclesiástico que fuere expelido del país por enemigo de la independencia y libertad americana, no perciba los emolumentos de su beneficio ${ }^{46}$. El razonamiento de Echagüe sigue en esta línea, pues afirma que, si les está prohibida la percepción de los frutos, lo más lógico es que estén prohibidos del beneficio, esto es, que no sean ya los curas propietarios. Aunque su opinión no es determinante, nos demuestra una de las tantas maneras como se quiso

45 AGN, Real fusticia, leg. 149, exp. 9, año 1825, f. 4.

46 AGN, Real fusticia, leg. 149, exp. 9, año 1825, f. 11v. El subrayado corresponde al documento. 
buscar una justificación a la provisión de curatos por concurso público, ya que primero había que eliminar la legalidad de la posesión de los curas emigrados.

Existen otros casos. Se consolidó la independencia con la batalla de Ayacucho en diciembre de 1824. Sin embargo, el Real Felipe del Callao sigue resistiendo el asedio de los patriotas. Tras sus muros se encuentran varios sacerdotes españoles y americanos. Esta situación es diferente a la antes mencionada, puesto que los curas no han emigrado, se hallan todavía en el Perú. El gobierno es consciente de ello, y por eso en un primer momento prefiere esperar la rendición de los castillos y oír los motivos de la emigración de estos sacerdotes antes que convocar a concurso: «... pues todavía permanecen en el territorio de la República, y aunque desnaturalizados, pueden acaso manifestar con el tiempo que conocen y son sensibles a los intereses de su Patria» ${ }^{47}$.

Los sacerdotes párrocos son necesarios, ello explica esta actitud de conciliación más que de represión política; ya no hay peligro de que se retorne al antiguo orden. Pero el problema grave sigue siendo el abandono de la feligresía. Nuevamente la Corte Superior dictamina la provisión en propiedad de los curatos cuyos beneficiarios estén en el fuerte del Callao. La vacancia se justifica por «muerte civil», por hallarse entre los enemigos de la República. También se contempla la posibilidad de que vuelvan a ejercer «... si en algún tiempo sinceran su conducta política» ${ }^{48}$.

En todos los casos expuestos, la determinación final fue la vacancia de los curatos de españoles y americanos separados de sus beneficios, sea que estuviesen o no en el Perú. Ambas situaciones supusieron una confrontación entre el antiguo y el nuevo régimen, un manejarse entre dos realidades complejas y determinantes para la política nacional y para la legitimidad del gobierno entre la feligresía peruana.

El problema seguía siendo la falta de sacerdotes en las parroquias. Paralelamente a las disquisiciones sobre la vacancia de los curatos de emigrados, la necesidad obligó a mirar hacia los clérigos regulares. El año 1825 Carlos Pedemonte, gobernador eclesiástico de La Libertad, advertía que la carencia de sacerdotes párrocos en esta diócesis era absoluta. Por ello, ante la proximidad del concurso público convocado, solicitó al gobierno considerar la posibilidad «... de disponer de varios religiosos beneméritos y admitirlos a la oposición expresada, sin que por parte de los Prelados regulares pueda hacer la menor resistencia a esta medida... ${ }^{49}$.

\footnotetext{
47 AGN, Real fusticia, leg. 149, exp. 9, año 1825, f. 6-6v.

48 AGN, Real Fusticia, leg. 149, exp. 9, año 1825, f. 7.

49 AGN, Real Fusticia, leg. 149, exp. 38, año 1825, f. 1.
} 
El mismo Pedemonte era clérigo regular, de la Congregación de San Felipe Neri5 ${ }^{50}$. Así las cosas, se aceptó esta solicitud para el departamento de La Libertad ${ }^{51}$.

En esos momentos la situación era de enorme desconcierto y preocupación por el futuro de las diócesis. Las noticias de provincias desamparadas de los auxilios espirituales eran cotidianas. Pero quizá más que esto, la preocupación se centraba en el desagrado y descontento -palabras cargadas de tinte político en esos momentos- de los pueblos y autoridades hacia el gobierno, al que imputaban inacción y descuido. Esta era la imagen que la feligresía tenía del poder político y del poder eclesiástico, y era potencialmente peligrosa; en el ínterin sabemos que la búsqueda de solución era parte del proyecto gubernamental, aunque muchos intereses cabían en ese afán.

El brazo regular fue mirado con mayor importancia de la que se le adjudicó en el siglo XVIII por la política borbónica. Ahora las cosas eran distintas, pues el clero secular se hallaba muy disminuido, así que, si era necesario reemplazar las parroquias con curas leales, los regulares que se propongan a curatos también tendrán que ser «regulares beneméritos» ${ }^{52}$. Se admitió, por tanto, a presbíteros regulares en los concursos de curatos $^{53}$. Las cosas cambiaron significativamente y, con seguridad, los descontentos se incrementaron.

Además de esta innovación, los regulares fueron tocados por el gobierno de Bolívar en otras cuestiones. En el Cuzco, por ejemplo, se reorganizaron las rentas y bienes de los betlemitas, mercedarios, agustinos y de los religiosos de San Buenaventura en pro de los nuevos colegios y de los hospicios que fundós4.

50 Pedro Grases (ed.), Gaceta del Gobierno del Perú, t. II, p. 61.

51 Elizabeth HERNÁNDEZ GARCÍA, Nuevo régimen, «seculares» problemas: el clero en Trujillo independiente, una aproximación (1821-1830), en Revista Peruana de Historia Eclesiástica, 13 (2011), p. 121.

52 AGN, Real fusticia, leg. 149., exp. 38, año 1825, f. 1-2v.

53 Elizabeth HERNÁNDEZ GARCÍA, Nuevo régimen, «seculares» problemas: el clero en Trujillo independiente, una aproximación (1821-1830), en Revista Peruana de Historia Eclesiástica, 13 (2011), p. 121.

54 Cuzco, 8 de julio de 1825 . « $1^{\circ}$ Que se funden dos Hospicios con el título de Hospicios del Cuzco. $2^{\circ}$ Que a esta fundación concurran tres conventos de esta ciudad hasta completar la cantidad de siete mil quinientos pesos anuales. $3^{\circ}$ Que el Convento de la Merced ceda para este objeto fincas abonadas cuyo rédito sea de tres mil pesos. $4^{\circ}$ Que el de Santa Clara ceda otras fincas cuyo rédito sea de dos mil y quinientos pesos. $5^{\circ}$ Que el Convento de San Agustín ceda otras cuyo rédito sea de dos mil pesos. $6^{\circ}$ Que para el Hospicio de Expósitos y Huérfanos se destine la Casa de los religiosos de San Buenaventura, y para el de Inválidos y Mendigos de ambos sexos la que actualmente sirve de Hospital. $7^{\circ}$ Que los religiosos de San Buenaventura se agreguen al convento grande de San Francisco, en el cual subsistirán de los emolumentos de que han subsistido hasta ahora. $8^{\circ}$ Que el Hospital General se traslade al convento de los Betlemitas, en el cual residirán los padres de San Juan de Dios consagrados por su instituto al cuidado de los enfermos». Cuzco, 19 de julio de 1825. (Pedro Grases [ed.], Gaceta del Gobierno del Perú, t. III, p. 82). 
La constitución vitalicia de 1826 sostenía en su artículo 147 que eran enajenables todas las propiedades «... aunque pertenezcan a obras pías, a religiones o a otros objetos ${ }^{55}$. Pero con seguridad el cambio más importante fue la reforma de regulares del año 1826, medida que ha sido ya vista por la historiografía, aunque seguimos insistiendo que sería interesante analizar no solo su aplicación paulatina sino además su impacto en la población afín a sus religiosos ${ }^{56}$. Por último, en octubre del mismo año el gobierno envió una nota a las autoridades eclesiásticas afirmando que convenía suprimir algunas fiestas religiosas, puesto que eran ocasión de vicio, ocio y, hasta cierto punto, de inmoralidad ${ }^{57}$. Se trataba, en resumidas cuentas, de una situación de inusitada intromisión de la política en la esfera eclesiástica, y de acatamiento del clero a las disposiciones del Ejecutivo.

\section{LOS INTENTOS DE Bolívar CON LA SANTA SEDE}

Paralelamente a todos los nombramientos realizados y a las reformas eclesiásticas llevadas a cabo, el gobierno de Bolívar incidió en la necesidad de comunicarse con la Santa Sede, la cual también buscaba modos de estrechar lazos al otro lado del Atlántico. Roma decidió enviar a Sudamérica a Mons. Giovanni Muzi como vicario apostólico, llegando a Buenos Aires y a Santiago de Chile en enero y mayo de 1824, respectivamente. Esta Misión es muy importante en la historia de las relaciones entre la Santa Sede e Hispanoamérica. A través de ella, el Papa recibió de primera mano y de fuente confiable las noticias sobre la situación del clero en estas provincias. Es por ello que, como afirma Ayrolo, la Misión Muzi puede considerarse como el dispositivo que logró desembarazar la comunicación entre el Papa y Sudamérica, atribuyéndole un lugar en el mapa de las relaciones interestatales ${ }^{58}$.

En efecto, la llegada de Giovanni Muzi a Sudamérica generó gran expectativa en el clero y en las repúblicas americanas. Apenas tuvo noticia Bolívar de la llegada de Mons. Muzi, hizo que el Ministro de Gobierno, José Sánchez Carrión,

55 Juan José RUDA SANTOLARIA, Las relaciones entre la Iglesia y el Estado a la luz de las constituciones peruanas del siglo XIX, en Revista de Estudios Histórico-furídicos, XXIV (2002), p. 60.

56 Elizabeth HERNÁNDEZ GARCÍA, Hacia el control del clero piurano: la reforma de regulares de 1826 en el norte del Perú, en Francisco Cervantes, Lucrecia EnRíquez, Rodolfo AguirRe (eds.), Tradición y Reforma en la Iglesia Hispanoamericana, 1750-1840, México, 2012, p. 83.

57 Ernesto RojAS INGUNZA, El báculo y la espada..., op. cit., pp. 103-105.

58 Valentina AYROLO, Funcionarios de Dios y de la República. Clero y política en la experiencia de las autonomías provinciales, Biblos, Buenos Aires, 2007, pp. 40-41. 
le dirigiese una carta (13/07/1824) en la que le manifestaba los «ardientes deseos» de entrar en relaciones con Roma, «por demandarlo urgentemente la salud espiritual de estos pueblos, el estado de orfandad a que se hallan reducidas sus Iglesias y el espíritu de fidelidad a la doctrina ortodoxa, depositada en la religión santa que profesa la república». Pero Bolívar fue más allá, pidiéndole en esta carta un Concordato entre la Santa Sede y el gobierno del Perú ${ }^{59}$.

Muzi respondió a la carta con amabilidad y entusiasmo, afirmando dar cuenta a Su Santidad de los deseos expresados por el gobierno peruano. Pero no se pudo hacer mucho al respecto. Solo en parte se dieron algunas concesiones para el Perú por la Santa Sede. Pedemonte obtuvo que se le concediese la facultad de administrar el sacramento de la confirmación, y el gobierno obtuvo también que se aprobara la reducción de los días festivos ${ }^{60}$, reforma que se había hecho circular mucho antes del visto bueno de Roma y que había generado un gran rechazo en la población del sur andino, sobre todo por la justificación de tal medida ${ }^{61}$.

Pero si bien para las Provincias Unidas del Río de la Plata, esta Misión pudo ser un respiro, no fue efectiva en Chile, volviendo Muzi a Italia y deteniéndose momentáneamente las tratativas con la Santa Sede ${ }^{62}$. No se puede decir mucho más de estos intentos, pues poco tiempo después Simón Bolívar abandonaba este territorio en dirección a la Gran Colombia, donde había muchos más problemas que enfrentar. En 1827 al Libertador se le cerraron las puertas de la República peruana, y los temas relacionados al Patronato Regio fueron asumidos por los siguientes presidentes, así como cualquier intento de solución entre aquella institución y la Santa Sede.

\section{CONCLUSIÓN}

Aunque los siguientes años se pusieron en ejecución varias reformas eclesiásticas más, la inspiración más fuerte en ese poder civil sobre la Iglesia, en esa reeducación de la población a través del discurso religioso, se gestó durante el

59 Rubén VARgas UGarTe, Historia de la Iglesia..., op. cit., t. v, p. 106.

60 Ibid., pp. 106-107.

61 Circuló entre las autoridades eclesiásticas una nota en que se decía que, como las fiestas religiosas eran ocasión de ocio, vicio e incluso de brotes de inmoralidad entre la población, convenía suprimir algunas. Esta medida coincidía con otra que se aplicó más adelante: la reforma de regulares, en 1826. Con esto el gobierno se permitió demostrar ante la Iglesia y la población quién mandaba en el país (Ernesto ROJAS INGUNZA, El báculo y la espada..., op. cit., p. 104).

62 Más adelante la Santa Sede envió a Monseñor Ostini como Nuncio Apostólico, el cual se instaló en Río de Janeiro en 1830. 
gobierno de Simón Bolívar, hasta el punto que Ernesto Rojas afirma que, dos años después de Ayacucho, la Iglesia en el Perú se encontraba casi de rodillas ${ }^{63}$.

A Simón Bolívar le tocó vivir un período inestable y conflictivo en el Perú. Por un lado, la guerra en el campo de batalla fue una gran preocupación, estaba en ello su prestigio y la seguridad de Sudamérica. Sin saberlo a ciencia cierta, arribó a una República dividida, con una población agotada y expectante. Además, Bolívar fue testigo y víctima de las disputas entre los miembros de la clase dirigente peruana, heredera de una independencia frágil e inconsistente. Finalmente, y junto con ello o a consecuencia de lo dicho antes, se encontró un estamento eclesiástico de honda raigambre hispánica y monárquica con el que chocó, sobre todo, en las regiones que aún se mantenían fieles a la metrópoli.

Pero el clero era una pieza clave en el nuevo orden que Bolívar empezó a establecer. Si bien la institución eclesiástica en el Perú fue atacada por el gobierno dictatorial del Libertador desde distintos ángulos, en el fondo, pensamos, todo se dirigía a un mismo punto u objetivo: restarle poder en el imaginario colectivo de la población, disminuir su capacidad de reacción y someter las voluntades de sus miembros, regulares y seculares. San Martín pensaba también en esta línea, pero el enfrentamiento no fue tan directo. El hacerse de las prerrogativas del Patronato Regio nombrando obispos y párrocos, suprimiendo días festivos, uniendo territorios en las diócesis y reestructurando algunas canonjías y emolumentos, eran acciones de gran radicalidad. No se trataba de una inflexión en las relaciones Iglesia-Estado, era un antes y un después en la historia de la Iglesia en el Perú. Por eso el estudio de Bolívar y de su actuar en este ámbito reviste una importancia capital.

Fueron pocos los años de estancia de Simón Bolívar en el Perú (1823-1826), pero fueron suficientes para iniciar la reorganización de toda la institución eclesiástica, marcando un camino de secularización y de control en el que ya no hubo marcha atrás.

63 Ernesto Rojas INGUNZA, El báculo y la espada..., op. cit., p. 105. 